\title{
Functional Capacity and Risk Factors in Elderly Trauma Victims \\ ORIGINAL
}

\section{Abstract}

Objective: To determine changes in the functional capacity of elderly victims of external-cause trauma using the Modified Barthel Index and to evaluate related independent risk factors during hospitalization and ninety days after discharge.

Method: This prospective study of 247 elderly trauma victims in northeastern Brazil aged $\geq 60$ years. Data were analyzed using the software BioEstat 5.0. The Wilcoxon test was used with a significance level of $5 \%$. The independent predictors of incapacity that showed interactions $(p<0.2)$ with the outcome were evaluated using logistic regression with a stepwise selection model and adjusted odds ratios with a confidence interval of $95 \%$. This study was approved by the Research Ethics Committee.

Results: The mean age was 70.8 years, and the mean duration of hospitalization was 10.5 days. The logistic regression analysis showed that a history of cardiovascular disease, traumatic brain injury and femoral neck fracture were independent factors associated with moderate/severe functional incapacity in elderly trauma patients during hospitalization. Ninety days after discharge, associated factors were female gender, age greater than or equal to 80 years and femoral neck fracture.

Conclusion: The Modified Barthel Index showed improvement in functional capacity in almost all categories, except for elderly who remained in wheelchairs during hospitalization and 90 days after hospital discharge, with evidence of independent factors associated with incapacity, particularly femoral neck fracture. Studies involving the elderly can scientifically support the formulation of public policies.
Mariangela da Silva Nunes ${ }^{1}$, Edilene Curvelo Hora Mota ${ }^{1}$, Paulo Ricardo Saquete Martins-Filho', Ricardo Fakhouri", José Antonio Barreto Alves ${ }^{1}$, Maria do Carmo de Oliveira Ribeiro',

Alberto Correa de Vasconcellos ${ }^{1}$

1 Federal University of Sergipe, Aracaju, Sergipe, Brazil.

\section{Contact information:}

\section{Mariangela da Silva Nunes.}

Address: Department of Nursing, Federal University of Sergipe, Sergipe, Brazil, 490400-000.

झ prof.mariangela.den@gmail.com

Keywords

Elderly; Activities of Daily Living; Risk Factors; Wounds and Injuries; Hospitalization. 


\section{Introduction}

Population aging and urbanization represent a huge challenge for the $21^{\text {st }}$ century as increased life expectancy results from fundamental gains in public health and living standards of the population. The elderly are considered productive and in many cases are a resource for their families and economies. They have therefore also become more exposed to risks during daily living and work activities [1, 2]. Risks to which the elderly are exposed can contribute to a decrease in the loss of functional capacity and quality of life. Functional capacity has become a new health paradigm and should reflect the functionality with which the individual performs daily living activities. When an elderly individual starts to depend on other people to perform these activities, it may be considered detrimental to their functional independence, social relationships and activities at more advanced ages [3, 4].

External causes such as physical violence, trauma, falls and traffic accidents have a great social and economic impact, involving long-term hospitalization and rehabilitation of the victim, which can vary according to the severity of the injury suffered and have lifelong physical and psychological consequences [5].

The occurrence of falls among the elderly is associated with several factors such as comorbidities and physiological changes due to aging, which may contribute to clinical complications after trauma [6]. In Brazil, it is clear that for the elderly to age in a healthy manner, special attention should be given to this population in public health policies regarding the maintenance of capacity and muscle strength through the encouragement of a healthier lifestyle [7].

The Modified Barthel Index (MBI) is one of the various instruments used to determine functional capacity. It was originally developed to monitor the performance of patients hospitalized for an extended time, with paralysis conditions before and after treatment, and to indicate the medical care neces- sary for such patients [8]. Due to its ease and speed of application, the $\mathrm{MBI}$ is now used as an evaluation instrument for neurological and musculoskeletal disorders and to predict hospitalization time, prognostics and consequences of discharge [9].

The MBI may be used on adults, not necessarily the elderly, with neuromuscular disorders such as stroke, spinal cord injuries and multiple sclerosis as well as for various musculoskeletal problems such as burns, heart disease, rheumatoid arthritis and amputations [10, 11].

The $\mathrm{MBI}$ evaluates daily living activities and functional independence through 10 activities/categories such as personal hygiene, bathing, feeding, toilet habits, climbing stairs, dressing, bladder control, bowel control, walking and/or use of a wheelchair and getting in and out of the chair/bed. Each category is scored according to the performance of the patient in performing the tasks independently, with some help or in a dependent manner and results in a total score that can range from 0 to 100 or can be scored in intervals that reflect the degree of dependency of the patients for daily living activities $[9,11,12]$. Cultural adaptation of the MBI was performed and validated for Brazil in 2004, and the instrument may help to prevent or delay the onset of disability $[13,14]$.

The objectives of this study were to determine changes in the functional capacity of elderly victims of external-cause trauma using the Modified Barthel Index and to evaluate independent risk factors for trauma in the elderly in terms of functional capacity.

\section{Method}

\section{Study Design}

This work was a prospective study of elderly victims of external-cause trauma who were admitted to a public hospital, a reference center for trauma victims, in the state of Sergipe, northeastern Brazil. 
The patients were monitored from admission to 90 days after hospital discharge. Data were collected from March to November 2013 in the hospital and at the victim's home. This study was entirely submitted and formally approved by the Research Ethics Committee at Federal University of Sergipe under protocol number 12629713.1.0000.5546. The identity and the rights of participants were preserved, as required by the National Board of Health of the Ministry of Health of Brazil, stated at Resolution number 466, edited in December 12, 2012. All elderly trauma victims voluntarily agreed to participate in this study by signing a writing consent. For those elderly trauma victims that coud not sign a writing consent because of cognitive, hearing/talking or visual disturbances or disorders, the writing consent was obtained by a legally authorised representative. This consent procedure was approved by the Research Ethics Committee at Ferderal University of Sergipe.

\section{Eligibility criteria}

The convenience sample was non-probabilistic, chosen according to the spontaneous demand of elderly trauma victims who met the following inclusion criteria: both genders, $\geq 60$ years, victim of external-cause trauma such as motor vehicle accidents, accidental injury, self-harm and physical violence; having been admitted to the emergency department within 48 hours after trauma; accompanied by family member or caregiver so that possible cognitive, auditory, visual or speech disorders did not hamper application of the evaluation instrument; agreed to participate in the study voluntarily or through the permission of caregivers or family members in the case of cognitive and/ or hearing impairment. The following were considered to be exclusion criteria for elderly victims of external-cause traumas: events of undetermined intent, medical and surgical care complications, unclassified external causes and refusal to participate in the study.

\section{Sample Size Calculation}

For calculation of the sample size, the total number of elderly victims of external-cause trauma hospitalized between January and December 2011 was used, according to data from the Hospital Information System of the Unified Health System (Sistema Único de Saúde), with an error of tolerance of $5 \%$. A goal was set for the selection of at least 279 elderly victims of external-cause trauma.

\section{Glasgow Coma Scale (GCS)}

The level of consciousness was measured by the GCS for all elderly trauma victims upon admission [15-17]. The patients were categorized into three groups according to the following scale: 3-8 major trauma, 9-12 moderate trauma and 13-15 mild trauma [18]. Variables related to gender, age, mechanism of injury, preexisting conditions and type of injury were also collected.

\section{Modified Barthel Index (MBI)}

The $\mathrm{MBI}$ was used to evaluate functional capacity as reported by the patient, caregiver or family member as well as through direct observation by the researchers, based on descriptions of daily living activities relating to self-care, mobility, locomotion and evacuations. When the elderly victim was not able to read the questionnaire, the caregiver or the researchers read it so that he or she could respond. When the person was unconscious, physical examination determined the ability to perform the activities studied.

The sum of the values obtained in each activity produced a total score of 0-100. The elderly were categorized into two groups to determine the impairment of functional capacity: moderate to severe impairment (0-75 points) and light impairment to complete independence (76-100 points). The relationship between these groups and the clinical variables studied was then tested. Ninety days after hospital discharge, functional capacity was reevaluated at the victim's home. To facilitate pairing of the sample of the elderly during hospitalization and 
90 days after discharge, all deaths were excluded. Thus, 247 reevaluations were performed.

\section{Statistical Analysis}

The data were stored and analyzed using the software BioEstat 5.0. The dependent variable was functional capacity measured by $\mathrm{MBI}$ and was expressed as the median (interquartile range). The values obtained during hospitalization and 90 days after discharge were compared using the Wilcoxon test at a significance level of $5 \%$. Independent predictors of moderate to severe dependence during hospitalization and 90 days after discharge were initially evaluated using univariate logistic regression to reduce the number of potential confounders.

Subsequently, a multivariate logistic regression model was developed that incorporated the variables that had shown modest interactions $(p<0.2)$ with the outcome of interest. These variables were entered into the model using stepwise selection and an adjusted odds ratio with 95\% confidence interval and were used to determine the risk factors associated with moderate to severe dependence at both evaluation time points.

\section{Results}

A total of 282 elderly victims of external-cause trauma were hospitalized during the study period. Of these patients, 30 died during hospital monitoring, and 5 died at home after being discharged. The final sample thus consisted of 247 elderly victims.

The mean age of patients completing the study was $70.8 \pm 9.5$ years, with a mean hospital stay of $10.5 \pm 15.6$ days. The MBI evaluation during hospitalization and 90 days after hospital discharge showed change with improved functional capacity in almost all surveyed categories, except for elderly victims who remained in a wheelchair 90 days after the trauma, for whom an increase in the level of dependency was observed (Table 1), as demonstrated by the inability to move the chair over small distances
Table 1. Modified Barthel Index categories during hospitalization and 90 days after hospital discharge.

\begin{tabular}{|c|c|c|c|}
\hline Category & $\begin{array}{l}\text { Hospitalization } \\
\text { P50 (P25-P75) }\end{array}$ & $\begin{array}{l}90 \text { days after } \\
\text { discharge P50 } \\
\text { (P25-P75) }\end{array}$ & p-value \\
\hline $\begin{array}{l}\text { Personal } \\
\text { hygiene }\end{array}$ & $1.0(1.0-3.0)$ & $4.0(4.0-5.0)$ & $<0.0001$ \\
\hline Bathing & $1.0(1.0-3.0)$ & $4.0(4.0-5.0)$ & $<0.0001$ \\
\hline Feeding & $5.0(2.0-8.0)$ & $8.0(8.0-10.0)$ & $<0.0001$ \\
\hline Toilet habits & $2.0(0.0-5.0)$ & $8.0(8.0-10.0)$ & $<0.0001$ \\
\hline $\begin{array}{l}\text { Climbing } \\
\text { stairs }\end{array}$ & $0.0(0.0-5.0)$ & $8.0(5.0-10.0)$ & $<0.0001$ \\
\hline Dressing & $0.0(0.0-5.0)$ & $8.0(5.0-10.0)$ & $<0.0001$ \\
\hline $\begin{array}{l}\text { Bladder } \\
\text { control }\end{array}$ & $10.0(8.0-10.0)$ & $10.0(10.0-10.0)$ & $<0.0001$ \\
\hline $\begin{array}{l}\text { Bowel } \\
\text { control }\end{array}$ & $10.0(8.0-10.0)$ & $10.0(10.0-10.0)$ & $<0.0001$ \\
\hline Walking & $0.0(0.0-8.0)$ & $12.0(8.0-12.0)$ & $<0.0001$ \\
\hline Wheelchair & $5.0(0.0-5.0)$ & $0.0(0.0-0.0)$ & 0.0002 \\
\hline $\begin{array}{l}\text { Getting in } \\
\text { and out of } \\
\text { chair/bed }\end{array}$ & $3.0(0.0-8.0)$ & $12.0(8.0-12.0)$ & $<0.0001$ \\
\hline Total & $38.0(23.5-64.5)$ & $82.0(65.5-94.0)$ & $<0.0001$ \\
\hline
\end{tabular}

and confirmed by the median value, which decreased by 5 points.

Table 2 shows the association between the clinical variables studied and the level of dependency measured by the $\mathrm{MBI}$ during hospitalization. The frequency of moderate/severe functional dependence was significantly higher among elderly women

Table 2. Factors associated with moderate and severe dependency in elderly trauma victims during hospitalization.

\begin{tabular}{|c|c|c|c|c|}
\hline Variables & $\mathbf{n}$ & $\begin{array}{c}\text { Barthel } \\
\text { Index } \leq 75 \\
(\%)\end{array}$ & OR $(95 \% \mathrm{Cl})$ & p-value \\
\hline \multicolumn{5}{|l|}{ Gender } \\
\hline Male & 132 & $102(77.2)$ & \multirow{2}{*}{$2.5(1.2-5.2)$} & \multirow{2}{*}{0.017} \\
\hline Female & 115 & $103(89.5)$ & & \\
\hline \multicolumn{5}{|l|}{ Age (years) } \\
\hline $60-69$ & 136 & $105(77.2)$ & & \\
\hline $70-79$ & 58 & $48(82.7)$ & $1.4(0.6-3.1)$ & 0.499 \\
\hline$\geq 80$ & 53 & $52(98.1)$ & $10.8(1.3-87.8)$ & 0.017 \\
\hline
\end{tabular}




\begin{tabular}{c|c|c|c|c|} 
Variables & n & $\begin{array}{c}\text { Barthel } \\
\text { Index } \leq 75 \\
(\%)\end{array}$ & OR (95\% Cl) & p-value \\
\hline & & &
\end{tabular}

\section{Fall}

\begin{tabular}{|l|c|c|c|c|}
\hline Yes & 161 & $143(88.8)$ & $3.1(1.6-6.1)$ & 0.002 \\
\hline No & 86 & $62(72.1)$ & & \\
\hline
\end{tabular}

Traffic accident

\begin{tabular}{|l|c|c|c|c|}
\hline Yes & 54 & $46(85.1)$ & $1.2(0.5-2.8)$ & 0.799 \\
\hline No & 193 & $159(82.4)$ & & \\
\hline
\end{tabular}

Physical violence

\begin{tabular}{|l|c|c|c|c|}
\hline Yes & 17 & $9(52.9)$ & $0.2(0.07-0.5)$ & 0.002 \\
\hline No & 230 & $196(85.2)$ & & \\
\hline
\end{tabular}

History of endocrine disease

\begin{tabular}{|l|c|c|c|c|}
\hline Yes & 54 & $48(88.8)$ & $1.8(0.7-4.6)$ & 0.272 \\
\hline No & 193 & $157(81.3)$ & & \\
\hline
\end{tabular}

History of cardiovascular disease

\begin{tabular}{|l|c|c|c|c|}
\hline Yes & 191 & $169(88.4)$ & $4.2(2.1-8.6)$ & $<0.001$ \\
\hline No & 56 & $36(64.2)$ & & \\
\hline
\end{tabular}

History of respiratory disease

\begin{tabular}{|l|c|c|c|c|}
\hline Yes & 4 & $4(100.0)$ & $1.9(0.1-35.9)$ & 0.669 \\
\hline No & 243 & $201(82.7)$ & & \\
\hline History of musculoskeletal disease & & \\
\hline Yes & 134 & $118(88.0)$ & $2.2(1.1-4.3)$ & 0.032 \\
\hline No & 113 & $87(76.9)$ & & \\
\hline
\end{tabular}

History of neurological disease

\begin{tabular}{|l|c|c|c|c|}
\hline Yes & 17 & $17(100.0)$ & $7.9(0.5-133.8)$ & 0.152 \\
\hline No & 230 & $188(81.7)$ & & \\
\hline
\end{tabular}

History of psychiatric disease

\begin{tabular}{|l|c|c|c|c|}
\hline Yes & 7 & $6(85.7)$ & $1.2(0.1-10.5)$ & 0.752 \\
\hline No & 240 & $199(82.9)$ & & \\
\hline
\end{tabular}

History of neoplastic disease

\begin{tabular}{|c|c|c|c|c|}
\hline Yes & 3 & $3(100.0)$ & \multirow{2}{*}{$1.5(0.07-29.0)$} & \multirow{2}{*}{0.800} \\
\hline No & 244 & $202(82.7)$ & & \\
\hline \multicolumn{5}{|c|}{ Traumatic brain injury } \\
\hline Yes & 62 & 55 (88.7) & \multirow{2}{*}{$1.9(0.8-4.5)$} & \multirow{2}{*}{0.151} \\
\hline No & 185 & 150 (81.1) & & \\
\hline
\end{tabular}

Femoral neck injury

\begin{tabular}{l|c|c|c|}
\hline Yes & 87 & $86(98.8)$ & $29.6(4.0-219.6)<0.001$ \\
\hline No & 160 & $119(74.4)$ & $29(19.001$
\end{tabular}

Fracture of tibia and/or fibula

\begin{tabular}{|c|c|c|c|c|}
\hline Yes & 14 & $12(85.7)$ & \multirow{2}{*}{$1.2(0.3-5.8)$} & \multirow{2}{*}{0.930} \\
\hline No & 233 & $193(82.8)$ & & \\
\hline \multicolumn{5}{|c|}{ Thoracic trauma } \\
\hline Yes & 13 & $9(69.2)$ & \multirow{2}{*}{$0.4(0.1-1.5)$} & \multirow{2}{*}{0.328} \\
\hline No & 234 & $196(83.8)$ & & \\
\hline
\end{tabular}

\begin{tabular}{|c|c|c|c|c|}
\hline Variables & $\mathbf{n}$ & $\begin{array}{c}\text { Barthel } \\
\text { Index } \leq 75 \\
\text { (\%) }\end{array}$ & OR $(95 \% \mathrm{Cl})$ & p-value \\
\hline \multicolumn{5}{|c|}{ Rachimedular Trauma } \\
\hline Yes & 9 & $6(66.6)$ & \multirow{2}{*}{$0.4(0.1-1.6)$} & \multirow{2}{*}{0.380} \\
\hline No & 238 & $199(83.6)$ & & \\
\hline \multicolumn{5}{|c|}{ Upper limb fracture } \\
\hline Yes & 25 & $20(80.0)$ & \multirow{2}{*}{$0.8(0.3-2.3)$} & \multirow{2}{*}{0.888} \\
\hline No & 222 & $185(83.3)$ & & \\
\hline \multicolumn{5}{|c|}{ Glasgow Coma Score } \\
\hline $3-8$ & 5 & $5(100.0)$ & $2.6(0.1-48.3)$ & 0.518 \\
\hline $9-12$ & 27 & $26(96.2)$ & $6.1(0.8-46.5)$ & 0.080 \\
\hline $13-15$ & 215 & $174(80.9)$ & & \\
\hline
\end{tabular}

aged 80 years or over, victims of falls or physical violence, patients with a history of cardiovascular, musculoskeletal or neurological disease, patients who suffered traumatic brain injury (TBI) or femoral neck fracture and patients whose GCS score was between 9 and 12 points.

Table 3. Independent risk factors for moderate and severe dependency in elderly trauma victims during hospitalization with logistic regression analysis.

\begin{tabular}{|l|c|c|c|}
\hline \multicolumn{1}{|c|}{ Variable } & $\begin{array}{l}\text { Regression } \\
\text { coefficient }\end{array}$ & OR (95\% CI) & p-value \\
\hline $\begin{array}{l}\text { History of } \\
\text { cardiovascular } \\
\text { disease }\end{array}$ & 1.415 & $4.1(1.9-9.1)$ & 0.0005 \\
\hline $\begin{array}{l}\text { Traumatic brain } \\
\text { injury }\end{array}$ & 1.614 & $5.0(2.0-12.8)$ & 0.0007 \\
\hline $\begin{array}{l}\text { Femoral neck } \\
\text { fracture }\end{array}$ & 3.830 & $46.0(6.1-349.1)$ & 0.0002 \\
\hline
\end{tabular}

The results of the logistic regression analysis (Table 3) showed that a history of cardiovascular disease, TBI and femoral neck fracture were independent factors associated with moderate/severe functional incapacity in elderly trauma patients during hospitalization.

The frequency of moderate/severe functional dependency 90 days after hospital discharge (Table 4) was significantly higher among elderly females aged 70 years or older, victims of falls, traffic accidents or 
Table 4. Factors associated with moderate and severe dependency in elderly trauma victims 90 days after hospital discharge.

\begin{tabular}{|c|c|c|c|c|}
\hline Variables & $\mathrm{n}$ & $\begin{array}{c}\text { Barthel } \\
\text { Index } \leq 75 \\
(\%)\end{array}$ & OR $(95 \% \mathrm{Cl})$ & $p$-value \\
\hline \multicolumn{5}{|l|}{ Gender } \\
\hline Male & 132 & $29(22.0)$ & \multirow{2}{*}{$5.5(3.2-9.6)$} & \multirow{2}{*}{$<0.001$} \\
\hline Female & 115 & $70(60.9)$ & & \\
\hline \multicolumn{5}{|l|}{ Age (years) } \\
\hline $60-69$ & 136 & $26(19.1)$ & & \\
\hline $70-79$ & 58 & $28(48.3)$ & $4.0(2.0-7.7)$ & $<0.001$ \\
\hline$\geq 80$ & 53 & 45 (84.9) & $23.8(10.0-56.2)$ & $<0.001$ \\
\hline \multicolumn{5}{|l|}{ Fall } \\
\hline Yes & 161 & $143(88.8)$ & \multirow{2}{*}{$6.4(3.3-12.5)$} & \multirow{2}{*}{$<0.001$} \\
\hline No & 86 & $62(72.1)$ & & \\
\hline \multicolumn{5}{|c|}{ Traffic accident } \\
\hline Yes & 54 & $46(85.1)$ & \multirow{2}{*}{$0.4(0.2-0.7)$} & \multirow{2}{*}{0.004} \\
\hline No & 193 & $159(82.4)$ & & \\
\hline \multicolumn{5}{|c|}{ Physical violence } \\
\hline Yes & 17 & $9(52.9)$ & \multirow{2}{*}{$0.1(0.01-0.7)$} & \multirow{2}{*}{0.006} \\
\hline No & 230 & $196(85.2)$ & & \\
\hline \multicolumn{5}{|c|}{ History of endocrine disease } \\
\hline Yes & 54 & $48(88.8)$ & \multirow{2}{*}{$2.0(1.1-3.8)$} & \multirow{2}{*}{0.032} \\
\hline No & 193 & $157(81.3)$ & & \\
\hline \multicolumn{5}{|c|}{ History of cardiovascular disease } \\
\hline Yes & 191 & $169(88.4)$ & \multirow{2}{*}{$1.9(1.0-3.7)$} & \multirow{2}{*}{0.065} \\
\hline No & 56 & $36(64.2)$ & & \\
\hline \multicolumn{5}{|c|}{ History of respiratory disease } \\
\hline Yes & 4 & $4(100.0)$ & \multirow{2}{*}{$4.6(0.5-44.8)$} & \multirow{2}{*}{0.356} \\
\hline No & 243 & $201(82.7)$ & & \\
\hline \multicolumn{5}{|c|}{ History of musculoskeletal disease } \\
\hline Yes & 134 & $118(88.0)$ & \multirow{2}{*}{$1.8(1.1-3.0)$} & \multirow{2}{*}{0.042} \\
\hline No & 113 & $87(76.9)$ & & \\
\hline \multicolumn{5}{|c|}{ History of neurological disease } \\
\hline Yes & 17 & $17(100.0)$ & \multirow{2}{*}{$2.3(0.8-6.2)$} & \multirow{2}{*}{0.169} \\
\hline No & 230 & 188 (81.7) & & \\
\hline History of $p$ & chiatr & disease & & \\
\hline Yes & 7 & $6(85.7)$ & & \\
\hline No & 240 & 199 (82.9) & $1.1(0.2-5.1)$ & 0.811 \\
\hline History of $n$ & pplasti & disease & & \\
\hline Yes & 3 & 3 (100.0) & & \\
\hline No & 244 & $202(82.7)$ & $3.0(0.3-33.9)$ & 0.725 \\
\hline
\end{tabular}

\begin{tabular}{c|c|c|c|c} 
Variables & $\mathbf{n}$ & $\begin{array}{c}\text { Barthel } \\
\text { Index } \leq 75 \\
(\%)\end{array}$ & OR $(95 \% \mathrm{Cl})$ & p-value \\
\hline & & &
\end{tabular}

Traumatic brain injury

\begin{tabular}{|l|c|c|c|c|}
\hline Yes & 62 & $55(88.7)$ & $0.6(0.4-1.2)$ & 0.193 \\
\hline No & 185 & $150(81.1)$ & & \\
\hline
\end{tabular}

Femoral neck fracture

\begin{tabular}{|l|c|c|c|c|}
\hline Yes & 87 & $86(98.8)$ & $13.4(7.1-25.2)$ & $<0.001$ \\
\hline No & 160 & $119(74.4)$ & &
\end{tabular}

Fracture of tibia and/or fibula

\begin{tabular}{|l|c|c|c|c|}
\hline Yes & 14 & $12(85.7)$ & $0.4(0.1-1.4)$ & 0.236 \\
\hline No & 233 & $193(82.8)$ & &
\end{tabular}

Thoracic trauma

\begin{tabular}{|l|c|c|c|c|}
\hline Yes & 13 & $9(69.2)$ & $0.1(0.01-0.9)$ & 0.029 \\
\hline No & 233 & $196(83.8)$ & & \\
\hline
\end{tabular}

Rachimedular Trauma

\begin{tabular}{|l|c|c|c|c|}
\hline Yes & 9 & $6(66.6)$ & $0.4(0.08-2.0)$ & 0.443 \\
\hline No & 238 & $199(83.6)$ & & \\
\hline
\end{tabular}

Upper limb fracture

\begin{tabular}{|l|c|c|c|c|}
\hline Yes & 25 & $20(80.0)$ & $0.3(0.1-0.9)$ & 0.052 \\
\hline No & 222 & $185(83.3)$ & & \\
\hline
\end{tabular}

physical violence, patients with a history of endocrine, cardiovascular, musculoskeletal or neurological diseases and patients who had suffered TBI, femoral neck fracture, chest trauma or fracture of the upper limbs.

The results of the logistic regression analysis (Table 5) showed that female gender, age greater than or equal to 80 years and femoral neck fracture are independent factors associated with moderate/severe functional incapacity in elderly victims of external-cause trauma 90 days after discharge.

Table 5. Independent risk factors for moderate to severe dependency in elderly trauma victims 90 days after hospital discharge with logistic regression analysis.

\begin{tabular}{|l|c|c|c|}
\multicolumn{1}{|c|}{ Variable } & $\begin{array}{c}\text { Regression } \\
\text { coefficient }\end{array}$ & OR (95\% Cl) & p-value \\
\hline Female gender & 0.898 & $2.5(1.2-4.9)$ & 0.010 \\
\hline Age $\geq 80$ years & 2.024 & $7.6(3.5-16.2)$ & $<0.0001$ \\
\hline $\begin{array}{l}\text { Femoral neck } \\
\text { fracture }\end{array}$ & 2.050 & $7.8(3.8-15.9)$ & $<0.0001$ \\
\hline
\end{tabular}




\section{Discussion}

The longer life expectancy of the population in recent decades and the increasing social participation of older people both make the elderly more vulnerable to trauma and accidental injury. This study evaluated the functional capacity of hospitalized elderly trauma victims using the MBI. Evidence of significant functional impairment during hospitalization, including bladder and bowel control, was found in all categories. Despite the maximum $\mathrm{MBI}$ score being in the $50^{\text {th }}$ and $75^{\text {th }}$ interquartile, $25 \%$ of the sample needed supervision and presented incontinence due to loss of control of the bladder and anal sphincters. This result may be related to difficulty in accessing the toilet as a function of the functional impairment in walking, which showed the lowest value in the $25^{\text {th }}$ and $50^{\text {th }}$ interquartile.

However, 90 days after hospital discharge, a change was observed with improved functional capacity in almost all categories studied, except for the wheelchair category, which showed severe functional dependence after hospitalization. However, studies on elderly hospitalized due to external-cause trauma that relate capacities to $\mathrm{MBI}$ categories are still scarce, which makes comparative analysis difficult.

A score $\leq 75$ points on the $\mathrm{MBI}$ was considered to define moderate to severe dependency, as in previous studies [19-21]. Multivariate logistic regression revealed that at the time of hospitalization, the independent factors that showed a relationship with $\mathrm{MBI} \leq 75$ points were a history of cardiovascular disease, TBI and femoral neck fracture. Ninety days after hospital discharge, the independent factors were female gender with age $\geq 80$ years and femoral neck fracture, which showed a 46 times greater chance of loss of functionality. These results are similar to the results of studies that have shown a predominance of elderly women, 70 or older, fall victims [1, 2, 22-27], TBI [24, 28] and associated comorbidities [25, 29, 30].

To quantify the severity of TBI victims, many studies have used the GCS $[15,16,31]$ during the first
72 hours after injury, which can assist in predicting outcome and in determining the care necessary for the victim [17]. In this study, the majority of TBI victims had a GCS score between 13-15 points, which is considered mild trauma.

There may be a decrease in functional capacity in the elderly who are suffering from chronic diseases and do not adhere to treatment, which contributes to arterial complications and cardiovascular problems [25, 32] as well as increased likelihood of mortality, disability and cognitive impairment in older adults with endocrine disease such as diabetes mellitus [33]. The presence of musculoskeletal disease such as osteoporosis and the occurrence of falls are distinct conditions and, when associated, promote fractures in the elderly population, with increased morbidity and mortality [34].

In this study, there was a twofold increase in the risk of functional incapacity among patients with a history of musculoskeletal disease, both during hospitalization and 90 days after hospital discharge. However, the logistic regression analysis did not indicate a history of musculoskeletal disease as an independent factor. This result can be explained by the fact that musculoskeletal disorders are risk factors for femoral neck fracture; however, alone they cannot contribute directly to moderate to severe functional dependency.

The main orthopedic injury observed in this study was femoral neck fracture, which remained an independent risk factor for loss of functional independence during hospitalization and also 90 days after hospital discharge. Functional impairment in walking is directly related to femoral neck fracture and is also related to the elderly person remaining in bed with real difficulty in moving during hospitalization and also in the home after hospital discharge. Functional impairment in walking may contribute to skin lesions due to prolonged recumbence in bed and to absence from the economic and social activities that were performed before the traumatic event. 
The most common mechanisms of traumatic injury in the elderly are falls with a predisposition to femoral fracture [24, 35, 36]. Falls may be associated with the use of multiple drugs [37], the decline in functional activity, weakness and postural instability in walking $[6,38]$ indicating the need for specialized care to maintain conditions that favor recovery and quality of life.

However, the psychomotor reaction speed of individuals who have some difficulty with postural balance may be considered an important predictor of falls, as it is directly related to the responsiveness of the elderly at the time of the trauma event [27]. In this context, the maintenance of appropriate social activity after the occurrence of femoral fracture as a result of a fall represents a challenge for health professionals.

While the main limitation of this study was the lack of investigation of home environmental factors that might contribute to accidents and injuries or even hinder functional recovery of the elderly, its strength lies in the investigation of the functional capacity of elderly trauma victims using the $\mathrm{MBI}$, while hospitalized and at home, with no segment loss during analysis. The scarcity of published studies on this subject underlines its importance.

In summary, this study identified five risk factors associated with moderate to severe functional dependency in elderly victims of external-cause trauma, among which femoral neck fracture was particularly important because 90 days after hospital discharge, it remained a factor associated with functional impairment according to the MBI.

It is very important to address this subject in the elderly to scientifically support the development of public policies and decision-making aimed at this population group, which will allow the appropriate use of public resources for the promotion of disease prevention and improvement in the quality of life of the elderly.

\section{Disclosure statement}

The authors declare no conflict of interest.

\section{References}

1. Famà $F$, Murabito $M$, Beccaria $A$ et al. Polytrauma in geriatric patients: incidence and mortality. BMC Geriatr 2011; 11(suppl 1): A13.

2. Lima RS, Campos MLP. Perfil do idoso vítima de trauma atendido em uma Unidade de Urgência e Emergência. Rev esc enferm USP 2011; 45(3): 659-664.

3. Rosa TEC, Benicio MHD'A, Latorre MRDO, Ramos LR. Fatores determinantes da capacidade funcional entre idosos. Rev Saúde Pública 2003; 37(1): 40-48.

4. Aires M, Paskulin LMG, Morais EP. Capacidade funcional de idosos mais velhos: estudo comparativo em três regiões do Rio Grande do Sul. Rev Latino-Am. Enfermagem 2010 Jan-Feb; 18(1): [about $7 \mathrm{p.}$.]

5. Mello-Jorge MHPD, Koizumi MS. Gastos governamentais do SUS com internações hospitalares por causas externas: análise no Estado de São Paulo 2000. Rev Bras Epidemiol 2004;7(2): 228-238.

6. Rubenstein LZ. Falls in older people: epidemiology, risk factors and strategies for prevention. Age Ageing 2006; 35(S2): ii37ii41.

7. Instituto Brasileiro de Geografia e Estatística (IBGE) [cited 2013 Jul 20]. Available from: http://www.ibge.gov.br

8. Mahoney Fl, Barthel DW. Functional evaluation: the Barthel Index. Md State Med J 1965; 14: 61-65.

9. Nazzal M, Sa'Adah MA, Al-Ansaris D et al. Stroke rehabilitation: application and analysis of the modified Barthel index in an Arab community. Disability \& Rehabilitation 2001; 23(1): 36- 42.

10. Shah S, Vanclay F, Cooper B. Improving the sensitivity of the Barthel Index for stroke rehabilitation. J Clin Epidemiol 1989; 42(8): 703-709.

11. Hocking C, Williams M, Broad J, Baskett J. Sensitivity of Shah, Vanclay and Cooper's modified Barthel Index. Clin Rehabil 1999; 13: 141-147.

12. Minosso JSM, Amendola F, Alvarenga MRM, Oliveira MAC. Validação, no Brasil, do Índice de Barthel em idosos atendidos em ambulatórios. Acta paul. enferm 2010; 23(2): 218-223.

13. Guimarães RB, Guimarães RB. Validação e adaptação cultural para a língua portuguesa de escalas de avaliação funcional em doenças cerebrovasculares: uma tentativa de padronização e melhora da qualidade de vida. Rev Bras Neurol 2004; 40(3): 5-13.

14. Nascimento CM, Ribeiro AQ, Cotta RMM et al. Factors associated with functional ability in Brazilian elderly. Arch Gerontol Geriatr 2012; 54: e89-e94. 
15. Teasdale G, Jennett B. Assessment of coma and impaired consciousness: a practical scale. Lancet 1974; 2: 81-84.

16. McNett M. A review of the predictive ability of Glasgow Coma Scale scores in head injured patients. J Neurosci Nurs 2007; 39(2): 68-75.

17. Settervall CHC, Sousa RMC, Silva SCF. Escala de Coma de Glasgow nas primeiras 72 horas após trauma cranioencefálico e mortalidade hospitalar. Rev Latino-Am. Enfermagem 2011; 19(6): 1337-1343

18. Teasdale GM, Murray L. Revisiting the Glasgow coma scale and coma score. Intensive Care Med 2000; 26(2): 153-154.

19. Ronning OE, Guldvog B. Outcome of subacute stroke rehabilitation: a randomized controlled trial. Stroke 1998; 29: 779-784

20. Saxena SK, Ng TP, Yong D, Fong NP, Gerald K. Total direct cost, length of hospital stay, institutional discharges and their determinants from rehabilitation settings in stroke patients. Acta Neurol Scand 2006; 114: 307-314.

21. Supervia A, Aranda D, Màrquez A et al. Predicting length of hospitalisation of elderly patients, using the Barthel Index. Ageing 2008; 37(3): 339-342

22. Giannoudis PV, Harwood PJ, Court-Brown C, Pape HC. Severe and multiple trauma in older patients: incidence and mortalitaty. Injury 2009; 40: 362-367.

23. Adam SH, Eid HO, Barss $P$ et al. Epidemiology of geriatric trauma in United Arab Emirates. Arch Gerontol Geriatr 2001; 47: 377382.

24. Sterling DA, O'Connor JA, Bonadies J. Geriatric falls: injury severity is high and disproportionate to mechanism. J Trauma 2001; 50: 116-119.

25. Roche JJW, Wenn RT, Sahota O, Moran CG. Effect of comorbidities and postoperative complications on mortality after hip fracture in elderly people: prospective observational cohort study. BMJ 2005; 331:1374

26. Staudenmayer K, Hsia RY, Mann NC, Spain DA, Newgard CD. Triage of elderly trauma patients: a population-Based perspective. J Am Coll Surg 2013; 217: 569-576.

27. Chen TY, Peronto $C L$, Edwards JD. Cognitive function as a prospective predictor of falls. J Gerontol B Psychol Sci Soc Sci 2012; 67(6): 720-728.

28. Kannus $P$, Sievanen $H$, Palvanen $M$, Jarvinen $T$, Parkkari J. Prevention of falls and consequent injuries in elderly people. Lancet 2005; 366: 1885-1893.

29. Juliebo V, Krogseth M, Skovlund E, Engedal K, Wyller TB. Medical treatment predicts mortality after hip fracture. J Gerontol A Biol Sci Med Sci 2010; 65A(4): 442-449.

30. Bergeron E, Clement J, Lavoie A et al. A simple fall in the elderly: not so simple. J Trauma 2006; 60: 268-273.

31. Heim D, Schoettker P, Spahn DR. Glasgow coma scale in traumatic brain injury. Anaesthesist 2004; 53(12): 1245-55.
32. Rodrigues RAP, Scudeller PG, Pedrazzi EC, Schiavetto FV, Lange C. Morbidade e sua interferência na capacidade funcional de idosos. Acta Paul Enfermagem 2008; 21(4): 643-648.

33. McGuire LC, Ford ES, Ajani UA. The impact of cognitive functioning on mortality and the development of functional disability in older adults with diabetes: the second longitudinal study on aging. BMC Geriatr 2006; 6: 8.

34. Cunnings-Vaughn LA, Gammack JK. Falls, Osteoporosis and hip fractures. Med Clin N Am 2011; 95: 495-506.

35. Ferrera PC, Bartfield JM, D'Andrea CC. Outcomes of admitted geriatric trauma victims. Am J Emerg Med 2000; 18: 575-580.

36. Abrantes KSM, Menezes TN, Farias MCAD, Casimiro GS, Videres ARN, Abreu LC. Trauma in Elderly People Attended by a Mobile Emergency Service. International Archives of Medicine 2015; 8(80):1-11.

37. Kojima T, Akishita M, Nakamura T et al. Polypharmacy as a risk for fall occurrence in geriatric outpatients. Geriatr Gerontol Int 2012; 12: 425-430.

38. Pereira SEM, Puts TEM, Portela MC, Sayeg MA. The impact of hip fracture (HF) on the functional status (FS) of older persons in Rio de Janeiro, Brazil: Results of a prospective cohort study. Arch Gerontol Geriatr 2010; 51(1):e28-35.

\section{Publish in International Archives of Medicine}

International Archives of Medicine is an open access journal publishing articles encompassing all aspects of medical science and clinical practice. IAM is considered a megajournal with independent sections on all areas of medicine. IAM is a really international journal with authors and board members from all around the world. The journal is widely indexed and classified Q2 in category Medicine. 